\title{
PHILOSOPHY OF INTERDISCIPLINARITY
}

\author{
Prof. Ph.D. Cecilia CURIS
}

Lecturer at Faculty of Medicine and Pharmacy/ Faculty of Arts,

"Dunarea de Jos" University of Galati, ROMANIA,

E-mail: Cecilia_curis@yahoo.com

\begin{abstract}
The interdisciplinary approach in science is becoming more widespread today. It is gratifying that in the age of applied sciences, in which technology prevails, philosophy as the core of the humanities is restored to its status. Starting from the definition of philosophy that includes notions such as knowledge, values, reason, existence, mind, language, it is not surprising the attitude of modern man in relation to the rational approach of including this fundamental discipline in scientific research in any field. This reconceptualization is absolutely necessary for the progress of humanity starting from the assumption that no field of scientific research can exist without a series of methodological principles. Consequently, we can consider philosophy, the theoretical foundation of any science and more than that, a science applied, per se with resonance in everyday existence. What can be more important for the human being than explaining the meaning of life, the relationship with peers and the psychological motivation of its existence in this world? Thus, philosophy can be the promoter of the active attitude of the individual in any social field. It is important to consider the model of the individual who from a moral point of view is interested, participatory, has a purpose and correctly defines his duties towards himself and society. These coordinates define the pattern of the human being capable of participating in the progress of humanity.
\end{abstract}

Keywords: interdisciplinarity; philosophy; science; humanity; progress;

\section{INTRODUCTION}

An analysis of the unprecedented evolution in science and art reveals us at a first view, without a doubt the fact that the interdisciplinary approach was the basis of this progress. It is obvious that a paradigm shift was needed to provide a favorable framework for making connections between border sciences or seemingly unrelated.

This article was born from the personal experience gained during the over 20 years of medical practice and in the field of psychology, as well as the almost 15 years of practice in education. The interdisciplinary approach has been a necessity from the beginning. Even though it was initially intuitively realized, over the years scientific knowledge in several fields has become an imperative in terms of professional development from the perspective of a person with academic training.

The purpose of this article is not to clarify the ontological or epistemological theoretical aspects of interdisciplinarity, but only to bring to the fore a number of essential aspects related to the advantages and why not, and of the risks of the interdisciplinary approach in science and philosophy, without he claimed to have found answers to resolve theoretical disputes at the academic level (Hofmann HG, Schmidt DC, 2011). In essence, it may in fact be the most vivid proof of the need for interdisciplinary knowledge. 


\section{THE FRAME OF REFERENCE AND THE NEED FOR SUSTAINABILITY}

Beyond the theoretical disputes related to the epistemological aspects of interdisciplinarity, (Danermark B., 2019, Welch J. IV, 2012), scientific policy currently credits interdisciplinary research through the existence of funding programs such as Horizon 2020 that aim to stimulate interdisciplinary research(Boon M., van Baalen, 2019). It is difficult to locate in time the notion of interdisciplinarity. Or maybe it's enough to look at the past. A review from a historical perspective of the philosophical evolution of science reveals that interdisciplinarity is not an attribute of our age, its origins being found in antiquity. A reference to the evolution of humanity could lead to the conclusion that interdisciplinarity has its origin even earlier, springing from a practical, existential necessity of the human being. Thus, since the dawn of humanity, individuals have intuited the existence in a primitive form of what we now call interdisciplinarity, as a possibility to facilitate survival in conditions where in a hostile world, knowledge gained individually was transferred and used together for the human's evolution. In an anthropological context, Antiquity represents a defining period for the manifestation of interdisciplinarity at individual level. The important representatives of this era are: Aristotle, Pythagoras, Democritus and Leucippus, thus mentioning only some of the pillars of ancient philosophy. Foreshadowing the concept of individualinterdisciplinarity and supraspecialisation Aristotle states: "First of all, we believe that the sage must know all things as far as possible, but without knowing them in detail" (Aristotle, Metaphysics, I, after Gomez Pin V., 2020 )

Moving on to the modern age, it is imperative to remember Decartes, the Parent of modern philosophy. His contribution to the evolution of the philosophy of science and implicitly of interdisciplinarity is essential. Thus, Decartes can be considered to be the first to try to establish a bridge between science and philosophy by establishing the boundaries of the new science of knowledge. This was possible due to the bidirectional contribution between science and philosophy. It would not be wrong to consider that in this way Decartes contributed to the unification of the theory of knowledge, establishing in a recognized way a bridge between what later was the basis for the birth of interdisciplinarity in the current sense. Moreover, it thus lays the foundation for the transition of interdisciplinarity from the individual to the collective level.

We cannot ignore the fact that in modern times the transition stage to what we call today an interdisciplinary approach was represented through the concept of integrative approach. At this point, it is necessary to mention what Erich Jantsch brings into discussion when referring to the notion of interdisciplinarity in relation to the integrative approach. Thus, interdisciplinarity also means the transfer of problems that can be solved through the problem-solving capacity of interdisciplinarity (Scmidt CJ, 2008), constituting a fruitful way to connect separate disciplines and in essence to achieve exactly what we call interdisciplinarity. (Thore'n H., Persson P., 2013)

Thus we arrive at another concept, namely, that of overspecialization, without which we cannot speak at present about interdisciplinarity. Thus it arrives at much discussed and disputed aspect namely that of the benefits and risks deriving from overspecialization in relation to interdisciplinarity. Studies show that "abandoning specialization in the face of moderate degrees of background interdisciplinarity impairs performance, but scientists who approach the notions of interdisciplinarity outperform those who specialize in all stages of their careers. An argument in favor of interdisciplinarity would be that the collaborative, interdisciplinary attitude favors the dissemination, a superior absorption of knowledge, their 
integration, as well as the synergistic creation of new knowledge. (Bonaventura M., Latora V., Nicosia V., Panzarasa P., 2017). Interdisciplinarity was used as a working tool in the quantification that was the basis for a classification that divides interdisciplinary researchers into four categories, with an impact in terms of the practice of interdisciplinarity. (Aram D.J., 2004).

\section{BRIEF HISTORY AND EVOLUTION OF INTERDISCIPLINARITY}

Given the current urgent need to redefine human knowledge, it is necessary to use the so-called "metacognitive scaffolding" to be used as working tool for analyzing and reconstructing the way knowledge is constructed and how these disciplines achieve this in a different. In interdisciplinary research, metacognitive scaffolding helps interdisciplinary communication in order to analyze and articulate how the discipline constructs knowledge". (Boon M., van Baalen, 2019).

Philosophy - "the love of wisdom" - has not been limited since its inception to theoretical notions. Thus, natural philosophy included astronomy, medicine, and physics, and Newton's treatise, "The Mathematical Principles of Natural Philosophy", printed in 1687, was framed as a book in the field of science, as belonging, of physic's domain.

Going to the present times, we discover that the philosophy of science studies hypotheses, foundations, methods, implications of science going to the pragmatic aspect, namely the use of scientific discoveries.

Analyzing the history of the evolution of philosophy and science, we notice that practical needs have determined the transition from theoretical notions or concepts to their practical application. This trend is increasingly visible in today's society whose pragmatism is defining. However, it is not possible to give up the theoretical aspects that give the conceptual framework, in any field. What must be emphasized is that it was absolutely necessary to maintain an evolutionary simultaneity between interdisciplinarity per se and the evolution of science and the arts. A synthesis of this harmonization, with the inherent dysfunctions, is exposed in an article that brings together in a historical-evolutionary way philosophical, scientific and artistic aspects representative for the approached subject. Thus, the problem of the limits of interdisciplinarity is also brought to attention: "Perhaps disciplines do not so much elevate and refine and complete themselves through interdisciplinary encounters. Perhaps instead they only temper and chasten one another, highlighting and making manifest their limits, their difference, their shortcomings, their places among a plurality, and even their relative blindnesses, simply because through interdisciplinary work they reveal themselves as "only" perspectives. (Fosl S.P., 2016)

To exemplify the need to return at this time to the philosophical roots of thinking in a current way, we can use an interdisciplinary approach that combines philosophy, psychology and neuroscience, called neurophilosophy (Smith Churchland P., 2020).

It is obvious that the great gain of interdisciplinarity was found exactly in the bidirectional transfer of approaches in scientific research, essentially representing a path to its progress. It is recognized and accepted today that some philosophers of science use current scientific discoveries to enrich philosophical knowledge. This is as logical as possible, otherwise we should accept that philosophy is limited only to classical philosophical currents without knowing a current evolution. Undoubtedly, "the philosophy of science is currently one of the most dynamic sectors of philosophy" (Moulines C.U., 2021). 
The literature provides examples of academic disputes on this subject. Thus, "although scientists often contribute to the field, many prominent scientists have felt that the practical effect on their work is limited; a popular quote attributed to physicist Richard Feynman goes, "Philosophy of science is about as useful to scientists as ornithology is to birds." In response, some philosophers (e.g. Craig Callender) have suggested that ornithological knowledge would be of great benefit to birds, were it possible for them to possess it. "(https://web.stanford.edu) The existing reservations regarding the philosophy of science arise from the non-existence of common possibilities of standardization, of some conceptual and approach differences and of the scientifically validated working tools for which the needle is currently represented by the philosophy of science. Let us not forget, however, that progress is born of the contradiction of ideas and accept that interdisciplinarity can provide a bridge even between philosophy and science, apparent fields without any connection. For this reason, an approach that transcends information interpenetration is required. Only in this way can the paradigm shift be justified.

At this point, it is impossible to approach the subject of the philosophy of interdisciplinarity without referring to the notions of modernism and postmodernism. In his work Modernism, Postmodernism, and Interdisciplinarity, Szostak clearly defines the connection between interdisciplinarity and the two philosophical currents, stating: "The key element of interdisciplinarity for the purposes of this paper, on general discussions of postmodernism and modernism." rather than detailed examination of primary work "] is that it reflects a belief that enhanced understanding of particular problems, issues, and themes is possible by integrating insights from different perspectives. " (Szostak R., 2007).

An aspect of interest of the approached topic is related to the perspectives of contemporary science and its management possibilities. It is suggested in this sense the way to resort to meta-analysis of existing data but also the use of methods validated and used in current research (interviews, experimental techniques, observational method, along with interventionist methods of approach) (Maki U., 2016)

A controversial issue regarding the allocation of funds in interdisciplinary research in the context of scientific policies (see Horizon 2020) is related to the benefits of interdisciplinarity compared to traditional disciplinary research. In the absence of evidence supported by studies, the relationship between interdisciplinarity and research performance remains uncertain, questionable and contested. (Mazzocchi F., 2019) Paradoxically, we are at the point where a method of practical approach already widely used is a subject of study from a conceptual and scientific point of view for which validation methods are sought in order to fit into the category of scientific methods based on evidence. (Okamura K., 2019).

\section{CONCLUSIONS}

The future will certainly offer us many situations in which solving complex problems will make the difference between survival and extinction, between well-being and regression. Ensuring a sustainable future requires training in multiple fields, a path that in the sense of those previously exposed falls within the pattern of interdisciplinarity. Until the validation specific through studies, we are in the situation where we can continue or abandon the interdisciplinary approach. Beyond the palpable evidence, the results obtained so far, undoubtedly support the need to acquire knowledge in several fields and to make the connection between them. Of course, it is difficult to us provide evidence on the sustainability of an approach free of scientific controversy. 
In order to help solve complex problems for a sustainable future, it is not enough for researchers to be well trained in their areas of expertise. They also need to understand the perspectives of experts in other disciplines. It is difficult to find arguments for sustainability that are free of scientific controversy. And yet, a look at the beginnings of knowledge can be an argument to continue.

\section{BIBLIOGRAPHY}

[1] Aram D.J.,(2004), Concepts of Interdisciplinarity: Configurations of Knowledge and Action, April 2004, Human Relations 57(4):379-412 DOI:10.1177/0018726704043893

[2] Bonaventura M., Latora V., Nicosia V., Panzarasa P.,(2017) The advantages of interdisciplinarity in modern science, https://arxiv.org/abs/1712.07910, Submitted on 21 Dec 2017, Cornell University.

[3] Boon M. , Van Baalen S.,(2018) Epistemology for interdisciplinary research - shifting philosophical paradigms of science, Eur J Philos Sci 2019;9(1):16.doi: 10.1007/s13194-018-0242-4. Epub 2018 Dec 12.

[4] Danermark B,(2019), Applied interdisciplinary research: a critical realist perspective, JOURNAL OF $\begin{array}{llllll}\text { CRITICAL REALISM 2019, VOL. } & 18, \quad \text { NO. } & 4, & 368-382\end{array}$ https://doi.org/10.1080/14767430.2019.1644983

[5] Fosl S.P., (2016) The many voices of interdisciplinarity, Cogent Arts \& Humanities, Volume 3, 2016 Issue 1, Article: 1164949| Published online: 04 Apr 2016

[6] Gomez Pin V., (2020), PITAGORA Copilaria filosofiei, Editura LITERA, Bucuresti 2020, ISBN 978606-33-4859-4

[7] Hofmann H.G, Schmidt D.C., (2011), Philosophy of (and as) Interdisciplinarity. Workshop Report (Atlanta, September 28-29, 2009), J Gen Philos Sci (2011) 42:169-175; DOI 10.1007/s10838-0119150-4, https://www.jstor.org/stable/41478445

[8] Interdisciplinarity in the Life Sciences and Their Philosophy, September 10th -14th, 2018, https://www.kli.ac.at/webroot/files/file/EASPLS\%20Programs/EASPLS18_Booklet-final30082018.pdf

[9] Mazzocchi F.,(2019) Scientific research across and beyond disciplines, Challenges and opportunities of interdisciplinarity, Science \& Society, DOI 10.15252/embr.201947682 | EMBO Reports (2019) 20: e47682 | Published online 30 April 2019

[10] Moulines U.C., (2021) POPPER SI KUHN Doi uriasi ai filosofiei stiintei din secolul XX, Editura LITERA Bucuresti, 2021, ISBN 978-60-33-7431-9.

[11] Okamura K., (2019), Interdisciplinarity revisited: evidence for research impact and dynamism, Palgrave Communications volume 5, Article number: 141 (2019), Humanities\& Social Sciences Communications, Published November 12, 2019

[12] Philosophy of Science, https://web.stanford.edu/class/symsys130/Philosophy\%20of\%20science.pdf. Pp 1-14

[13] Szostak R.,(2007) Modernism, Postmodernism, and Interdisciplinarity, ISSUES IN INTEGRATIVE STUDIES No. 25, pp. 32-83 (2007)

[14] Scmidt C.J.,(2008) Towards a philosophy of interdisciplinarity, February 2008, Poiesis \& Praxis 5(1):53-69, DOI:10.1007/s10202-007-0037-8

[15] Smith Churchland P.,(2020) Neurofilosofia, Editura Cartea Romaneasca Educational 2020, ISBN 978- 606-9088-93-7

[16] Thore'n H., Persson P.,(2013) The Philosophy of Interdisciplinarity: Sustainability Science and Problem-Feeding, J Gen Philos Sci (2013) 44:337-355 DOI 10.1007/s10838-013-9233-5, PP 338354, https://link.springer.com/content/pdf/10.1007\%2Fs10838-013-9233-5.pdf

[17] Uskali Mäki, (2016) Philosophy of interdisciplinarity. What? Why? How? Philosophy of Science, European Journal for Philosophy of Science volum 6, pagini327-342 ( 2016 ) Oct 4, 2016

[18] Welch J. IV, (2012) Interdisciplinarity and the Question of Being, ISSUES IN INTEGRATIVE STUDIES No. 30, pp. 99-127 